\title{
Inverse agonism: the classic concept of GPCRs revisited
}

\author{
Junichiro Sato $^{1{ }^{*}}$, Noriko Makita ${ }^{1}{ }^{*}$ and Taroh Iiri ${ }^{1), 2)}$ \\ 1) Department of Endocrinology and Nephrology, The University of Tokyo School of Medicine, Tokyo 113-8655, Japan \\ 2) Department of Pharmacology, St. Marianna University, Kawasaki 216-8511, Japan
}

\begin{abstract}
In the classical two-state model, G protein-coupled receptors (GPCRs) are considered to exist in equilibrium between an active and an inactive conformation. Thus, even at the resting state, some subpopulation of GPCRs is in the active state, which underlies the basal activity of the GPCRs. In this review, we discuss inverse agonists, which are defined as GPCR ligands that shift the equilibrium toward the inactive state and thereby suppress the basal activity. Theoretically, if constitutive activation plays an essential role in the pathogenesis of a disease, only inverse agonists, and not neutral antagonists, can reverse this pathophysiological activation. Although many pharmacological examples of inverse agonism have been identified, its clinical importance is still unclear and debated. Thus, even though inverse agonism of angiotensin receptor blockers (ARBs) has been discussed for more than 10 years, its clinical relevance remains to be completely clarified.
\end{abstract}

Key words: G protein-coupled receptor (GPCR), Inverse agonist, Antagonist, Angiotensin II type 1 receptor (AT1), Angiotensin receptor blocker (ARB)

G PROTEIN-COUPLED RECEPTORS (GPCRs) transduce extracellular signals into cells by activating trimeric $\mathrm{G}$ proteins [1-3]. About 800 GPCRs have been identified in mammals, each responding to a hormone, neurotransmitter, or sensory stimulus and activating one or more $\alpha \beta \gamma$ trimeric G proteins (composed of one of each of $16 \alpha, 5 \beta$, and $12 \gamma$ subunits). Agonistoccupied GPCRs activate $\mathrm{G}$ proteins by promoting the exchange of GTP for GDP bound to the $\alpha$ subunit of the $G$ protein $(G \alpha)$, generating two potential signaling molecules, $\alpha$-GTP and free $\beta \gamma$, and activating effector enzymes and ion channels [4-6]. GPCR ligands (such as agonists, antagonists, and inverse agonists) are classically considered to regulate the conformation of GPCRs. In addition, the conformation of GPCRs is allosterically regulated by interaction with $\mathrm{G}$ protein; $\mathrm{G}$ proteins were the first allosteric modulators of GPCRs

Submitted Feb. 17, 2016; Accepted Feb. 18, 2016 as EJ16-0084 Released online in J-STAGE as advance publication Mar. 8, 2016

Correspondence to: Noriko Makita, Department of Endocrinology and Nephrology, The University of Tokyo School of Medicine, 7-31 Hongo, Bunkyo-ku, Tokyo 113-8655, Japan.

E-mail: norimaki-tky@umin.ac.jp

Correspondence to: Taroh Iiri, Department of Pharmacology, St. Marianna University, 2-16-1 Sugao, Miyamae, Kawasaki 2168511, Japan. E-mail: tiiri-tky@umin.ac.jp

* J.S. and N.M. contributed equally.

(c) The Japan Endocrine Society to be identified. Interaction with $\mathrm{G}$ protein produces high-affinity binding of GPCR agonists. Agonists bind the active form of GPCRs (R 'on'), which interacts with $G$ proteins, with higher affinity than the inactive form of GPCRs ( $\mathrm{R}$ 'off'), whereas antagonists bind R 'on' and R 'off' equally.

\section{GPCR activation model: classic vs. novel}

In the classical two-state model of GPCR activation, GPCRs are considered to exist in equilibrium between an inactive state and an active state [1, 7] (Fig. 1). This model explains why GPCRs show basal activity, that is, "signal leak", at the resting state in the absence of agonist stimulation. In addition, it is postulated that agonists shift the GPCR equilibrium toward the active form, whereas inverse agonists do the opposite, and that antagonists, especially neutral antagonists, competitively inhibit agonists without affecting the equilibrium, interacting with R 'on' and R 'off' equally (Figs. 1 and 2). However, several lines of evidence lend support to a multi-state model for GPCRs, in which these receptors can spontaneously adopt multiple active and inactive conformational states [7-11]. In this new model, each ligand is hypothesized to recognize and stabilize a specific conformation of each type of GPCR, leading to 
Classic GPCRs : Two-state model

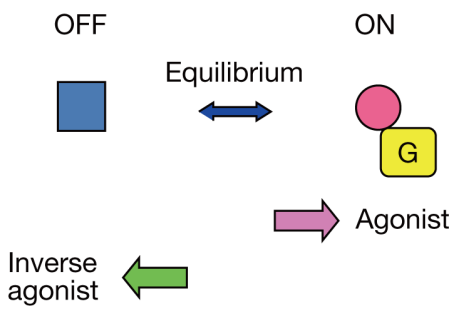

Antagonist

1) Competitively inhibits agonist action

2) Does not affect the equilibrium

Fig. 1 The classical two-state model of GPCR activation In the classical two-state model, the GPCR exists in equilibrium between an active state and an inactive state, explaining why GPCRs show basal activity in the resting state (please also see also Fig. 2). Agonists shift the equilibrium toward the active form, whereas inverse agonists do the opposite. Neutral antagonists are defined as GPCR ligands that competitively inhibit agonist action without affecting the equilibrium. Recently, however, accumulating evidence support an alternative multistate model for GPCRs. Based on this new model, the presence of neutral antagonists is being challenged.

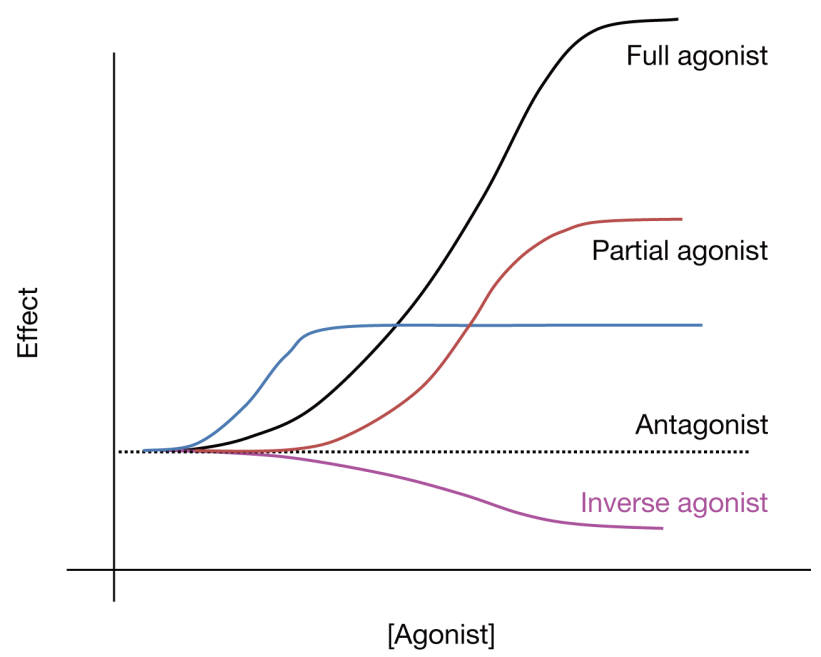

Fig. 2 The classification of GPCR ligands

GPCRs show basal activity at the resting state (please also see Fig. 1), the extent of which is different among GPCRs. Full and partial agonists show full and partial efficacy (GPCR activation), respectively. Inverse agonists stabilize the inactive form of GPCRs, thereby suppressing the GPCR activity below the basal levels. In the classical model, antagonists are defined as ligands that competitively inhibit agonist binding/action, unaffecting the GPCR equilibrium by themselves, and thus inhibiting the GPCR signal maximally to the basal levels. a set of unique and specific biological effects. Based on this model, the presence of neutral antagonists is being challenged. Essentially all antagonists, as defined classically, may, strictly speaking, be either partial agonists or inverse agonists (Figs. 1 and 2).

\section{Inverse agonism: why it has not been featured}

Although many examples of inverse agonism are well known pharmacologically [12-14], this issue has largely been ignored clinically. This may be at least partly due to the dogma that, as therapeutic drugs, neutral antagonists must be better than partial or inverse agonists because they do not change the resting state existing as a "gifted harmony" and inhibit only agonist-dependent signals. Logically, inverse agonists may shift and thus perturb the equilibrium between the inactive and active states of the GPCRs. If its basal activity in the resting state plays an important physiological role, the expression of the GPCR in question may be upregulated by a certain compensatory mechanism, causing the signal to be suppressed until it can over-rebound after the cessation of the inverse agonist. For example, histamine $\mathrm{H} 2$ antagonist, which decreases the production of gastric acid from parietal cells by blocking the action of histamine, is a representative inverse agonist [15]. It has been reported that cimetidine and ranitidine induce spontaneous agonist-independent $\mathrm{H} 2$ receptor activity by inducing $\mathrm{H} 2$ receptor upregulation in cultured cell lines $[16,17]$. Thus, the development of tolerance after prolonged clinical use and the recurrence of ulcer after sudden withdrawal of treatment may be caused, at least in part, by overactivation of $\mathrm{H} 2$ receptor signaling. However, their inverse agonist characteristics have not been emphasized, at least somewhat, because the main and most important role of $\mathrm{H} 2$ blocker is to block the action of histamine against $\mathrm{H} 2$ receptor as an antagonist. Similarly, in agonist-deficient knockout mice, the expression of the GPCR activated by the agonist may be upregulated [18].

\section{Spontaneous activation of GPCRs $v s$. inverse agonism}

In the setting of spontaneous activation of GPCRs, especially when this activation is accompanied by negative feedback suppression of their respective agonists, 
antagonists no longer work and only inverse agonists can inhibit the activation (Fig. 3) [12-14]. A constitutively active mutation of a GPCR $[13,19,20]$ is one of the representative situations that induce spontaneous GPCR activation. For example, congenital hyperthyroidism, neonatal inappropriate antidiuresis, and autosomal dominant hypocalcemia, caused by constitutively active mutations of the TSH receptor [21], V2 receptor [22, 23], and CaSR [24], respectively, can be treated not by neutral antagonists, but by inverse agonists. Besides constitutively active mutations, increased expression of GPCRs, allosteric activation, or existence of interacting proteins including GPCR dimerization might lead to a spontaneous (autonomous) activation of GPCRs (Fig. 4).

\section{Heart failure and AT1 signaling}

The past two decades have witnessed marvelous advances in the understanding of the pathophysiology of chronic heart failure, leading to significant improvements in therapy [25-27]. Recognition of the deleterious effects of overactivation of the renin-angiotensin system (RAS) and AT1-Gq/G13 signaling [28-30], in addition to desensitization of cardioprotective $\beta$ AR-Gs signaling [31-33], has made RAS a major therapeutic target, whether systemically or regionally $[34,35]$. In many randomized, controlled trials, ACE inhibitor (ACEi) reduced morbidity and mortality more than comparators in patients with congestive heart failure and coronary heart disease [36-40]. After the cardioprotective effect of ACEi was established, angiotensin receptor blocker (ARB) was originally suggested as a candidate alternative or more promising drug for blocking the RAS because ACEi sometimes also causes cough and angioedema or loses effectiveness over time, called the escape phenomenon. As expected, the LIFE trial added further evidence that blockade of the RAS by ARB, as well as by ACEi, may provide cardiovascular protection beyond the blood-pressure lowering effect [41]. Moreover, the CHARM-Added trial revealed that the addition of candesartan to ACEi and other treatments leads to a further clinically important reduction in relevant cardiovascular events in patients with chronic heart failure and a reduced left ventricular ejection fraction [42]. This result was interpreted to be because ARB blocked the harmful effect of angiotenisn II (AII) produced by the redundant pathway ACEi cannot inhibit.

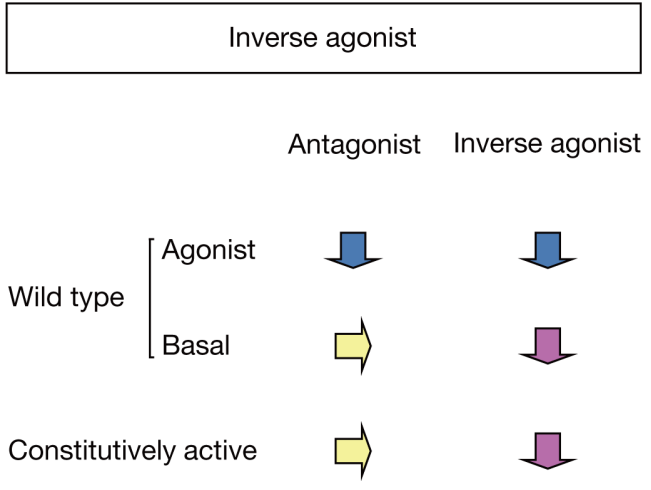

Inhibits autonomous activation of GPCR

Fig. 3 Inverse agonist $v s$. antagonist Inverse agonists shift the GPCR equilibrium toward the inactive form, whereas antagonists do not affect the equilibrium, competitively inhibiting the agonist action (please also see Fig. 1). Thus, both inverse agonists and antagonists inhibit agonist-dependent activation of GPCRs, whereas only inverse agonists, but not antagonists, inhibit autonomous activation of GPCRs, that is, basal activity of wild type GPCRs and increased basal activity of constitutively active mutant GPCRs.

Constitutive GPCR activation

OFF ON
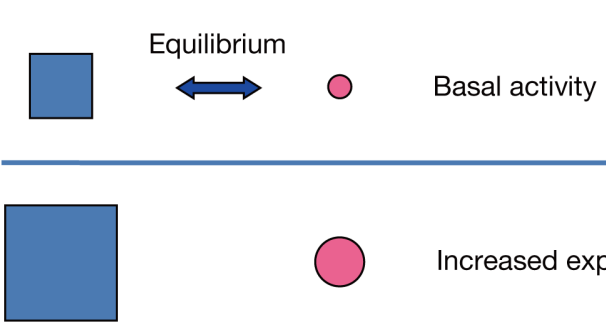

Increased expression
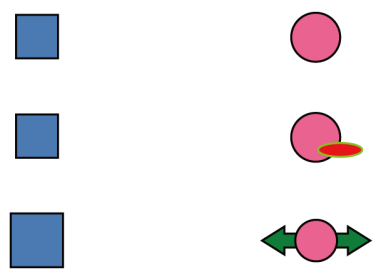

Constitutively active

Allosteric activation Interacting proteins

Mechanical stretch

Fig. 4 Mechanisms causing constitutive GPCR activation Constitutive GPCR activation can be caused by increased expression of GPCRs, constituticely active mutant GPCRs, allosteric activation, existing of interacting proteins includins GPCR dimerization that facilitate activation, or mechanical stretch (please also see Fig. 1). 


\section{Spontaneous activation of AT1 and ARBs}

If spontaneous activation of the AT1 receptor plays a major role in the overactivation of AT1-Gq/G13 signaling, the effect of ARBs may be explained by their inverse agonist activity, which we discovered for the AT1 receptor [43, 44] (Fig. 5). If this is the case, it may be expected that ARBs with inverse agonist activity would show a unique cardiovascular protective effect not shown by other antihypertensive drugs, including $\mathrm{ACEi}$, and that ARBs with stronger inverse agonist activity would show a greater cardioprotective effect. This would be in addition to the fact that add-on therapy of ARBs with inverse agonist activity to ACEi would show a greater cardioprotective effect. If these effects were proven in clinical trials, it would support the belief that the inverse agonist activity of ARB has vital effects beyond merely blocking the harmful effect of AII.

Although the initial data appeared to be positive [42], the subsequent clinical studies appeared to show negative results in chronic heart failure and cardiovascular diseases $[45,46]$. These findings may suggest that spontaneous activation of AT1 might not play as much of a role in the pathophysiology of chronic heart failure as initially speculated. Alternatively, we may have to consider the relative potencies of ARBs as inverse agonists when evaluating the results of clinical trials because inverse agonist activities vary among ARBs [43, 44] (Fig. 6). The question then arises as to how we can explain the data clearly showing that cardiac hypertrophy caused by mechanical stress in angiotensinogen knockout mice was inhibited by ARB treatment [43]. The artificial condition in which AT1 receptor was remarkably overexpressed as a result of a feedback mechanism caused by a lack of AII [18] might have led to this result because only an inverse agonist could inhibit such agonist-independent overactivity of the receptor. We may not then be able to directly apply the results of angiotensinogen knockout mice to the clinical settings, in which an agonist, AII, is not suppressed. Even when spontaneous activation of AT1 receptor occurs, AII-dependent AT1 activation may be dominant and ARB may act mainly as an antagonist to block the action by AII.

\section{The role of spontaneous AT1 activation}

The physiological role of mechanical stretch-dependent spontaneous activation of AT1 [43, 47, 48] is a

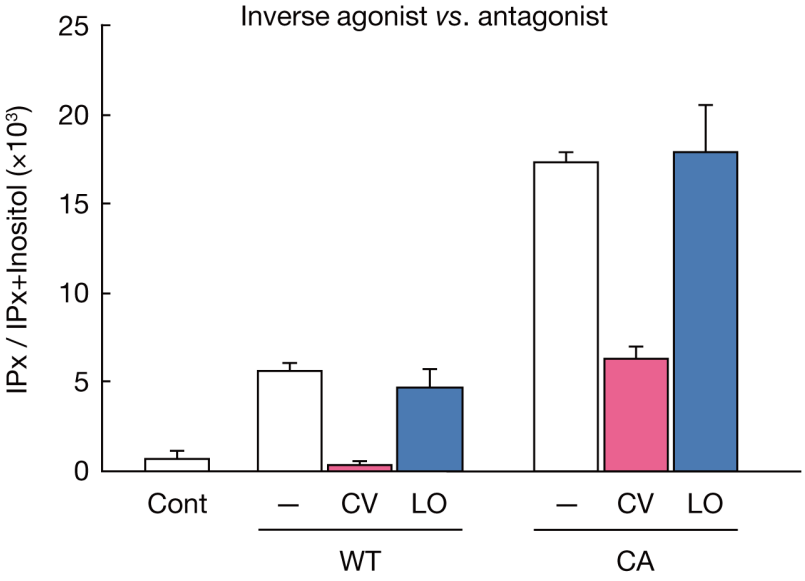

Fig. 5 ARBs: inverse agonist vs. antagonist When overexpressed in COS-7 cells, wild type (WT) and constitutively active (CA) AT1 receptor show basal activity and increased basal activity of Gq-dependent PI turnover signal, respectively (white). Candesartan (CV: $100 \mathrm{nM}$ ) acts as an inverse agonist, suppressing these activities below the basal levels (red), whereas losatrtan (LO: $100 \mathrm{nM}$ ) acts as an antagonist, unaffecting these activities (blue). (For details, please see the references $[10,43,44])$

principal question, especially when this activation is not accompanied by feedback inhibition of AII. We speculate that AII-dependent and spontaneous activation of AT1 may operate in a synergistic manner, that is to say, spontaneous activation of AT1 may be the machinery that potentiates AII-dependent AT1 activation in a cell-specific manner. Although these speculations have not been discussed nor clearly proven, interestingly, it has been reported that in vascular smooth muscle cells, mechanical stretch synergistically augments AII-dependent AT1 activation [49]. That report showed that the synergy is at least partly caused by augmented AT1 receptor expression and is inhibited by ARB. Even in that case, the main action of ARB may be due to its antagonist activity, although inverse agonist activity would have some effect against the overactivity of AT1 receptor due to augmented expression $[49,50]$.

\section{Clinical use of ARBs: inverse agonism and biased agonism}

How can we interpret the results of some clinical studies showing the benefits of ARB add-on, as in the CHARM-added study [42]? If ARBs show biased 
A

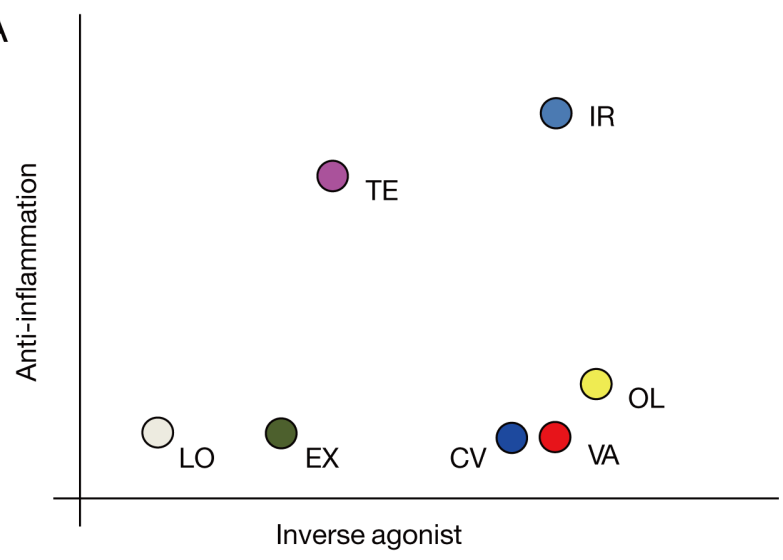

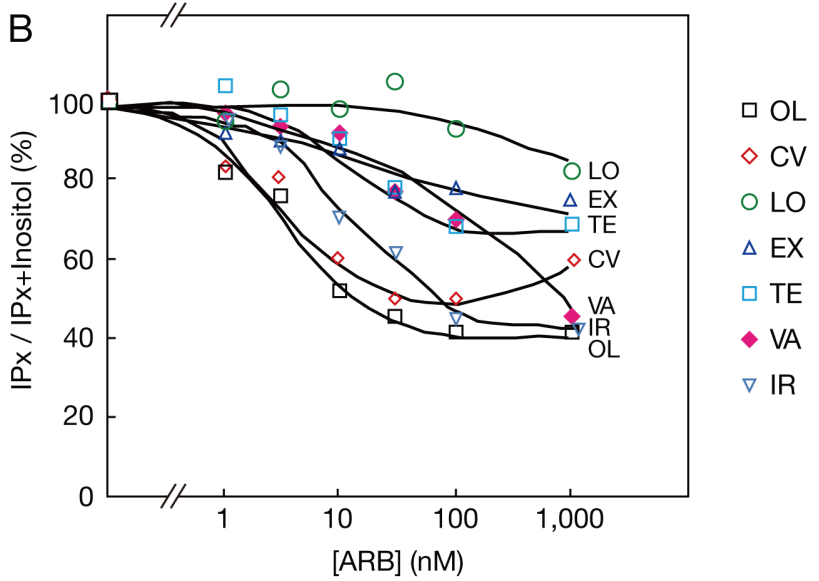

Fig. 6 ARBs: inverse agonist activity and anti-inflammation (A) ARBs and their metabolites are different in their inverse agonist activity and anti-inflammation effect (beyond AT1 effect). This anti-inflammation effect is likely to be via PPAR $\gamma$ activation and evaluated by the inhibition of MCP-1 and IL-6 secreted from cultured adipocytes. (B) Inverse agonist activity is quantitatively shown by the ARB (1-1,000 nM)-dependent inhibition of constitutively active mutant AT1 signals (Please also see Fig. 5 and its references). Data with olmesartan (OL), candesartan (CV), losartan (LO), EXP3174 (EX: an active metabolite of losartan), telmisartan (TE), valsartan (VA), and irbesartan (IR) are shown.

action, similar to that of beta-blockers [51,52], which inhibit one signaling pathway but do not inhibit the other, the ARB add-on effect might be explained. Indeed, a biased AT1 agonist and allosteric activation of AT1 have been reported [53, 54]. However, when attention first started being paid to the concept of biased agonism around 2007, it was rigorously examined whether ARB displays biased action. This hypothesis could not be proven however (Lefkowitz RJ, personal coummunication) [52]. Overall, accumulating data likely have failed to show the superiority of ARB against ACEi and the benefit of the ARB add-on effect to ACEi in cardiovascular protection [45]. Rather, some other metaanalysis reports have suggested that ACEi, but not ARB, may have the beyond blood pressure-lowering effect $[46,55,56]$. In addition, we might have to consider the differences among ARBs [57], including their inverse agonist activities (Fig. 6).

We can also speculate about some potential problems of ARBs if they do act as inverse agonists in the clinical settings. First, RAS over-rebound may occur when the action of ARBs is suddenly stopped. Second, problems might occur in pregnant patients. It has been reported that augmented AT1 signaling due to dimerization of AT1 and bradykinin receptor causes preeclampsia [58], although it is still being debated whether meaningful dimerization occurs
[59]. If ARBs were allowed to be prescribed during late pregnancy when teratogenicity is no longer a problem, they would be a useful treatment option for preeclampsia. In that case, the less inverse agonistic activity ARB shows, the more useful it might be, because such ARBs would hardly affect the basal equilibrium of AT1 during pregnancy.

\section{Conclusion}

In summary, now that we have extensive evidence of the benefits of ARBs in cardiovascular disease, it is time to reconsider the in vitro and in vivo data thus far obtained from artificial settings. This topic can be considered a good example of the importance of bidirectional reflection, not only from the bench to the bed, but also from the bed to the bench.

\section{Acknowledgment}

This work was supported by a Grant-in-Aid for Scientific Research from the Ministry of Education, Science, Sports, and Culture, Japan.

\section{Disclosure}

None of the authors have any potential conflicts of interests associated with this research. 


\section{References}

1. Gether U (2000) Uncovering molecular mechanisms involved in activation of $\mathrm{G}$ protein-coupled receptors. Endocr Rev 21 (1): 90-113.

2. Rockman HA, Koch WJ, Lefkowitz RJ (2002) Seventransmembrane-spanning receptors and heart function. Nature 415 (6868): 206-212.

3. Oldham WM, Hamm HE (2008) Heterotrimeric G protein activation by G-protein-coupled receptors. Nat Rev Mol Cell Biol 9 (1): 60-71.

4. Iiri T, Farfel Z, Bourne HR (1998) G-protein diseases furnish a model for the turn-on switch. Nature 394: 35-38.

5. Chung KY, Rasmussen SG, Liu T, Li S, DeVree BT, et al. (2011) Conformational changes in the G protein Gs induced by the beta 2 adrenergic receptor. Nature 477 (7366): 611-615.

6. Dror RO, Mildorf TJ, Hilger D, Manglik A, Borhani DW, et al. (2015) SIGNAL TRANSDUCTION. Structural basis for nucleotide exchange in heterotrimeric G proteins. Science 348 (6241): 1361-1365.

7. Makita N, Iiri T (2014) Biased agonism: a novel paradigm in $\mathrm{G}$ protein-coupled receptor signaling observed in acquired hypocalciuric hypercalcemia. Endocr $J 61$ (4): 303-309.

8. Hill SJ (2006) G-protein-coupled receptors: past, present and future. Br J Pharmacol 147 Suppl 1: S27-37.

9. Urban JD, Clarke WP, von Zastrow M, Nichols DE, Kobilka B, et al. (2007) Functional selectivity and classical concepts of quantitative pharmacology. $J$ Pharmacol Exp Ther 320 (1): 1-13.

10. Makita N, et al. (2007) An acquired hypocalciuric hypercalcemia autoantibody induces allosteric transition among active human Ca-sensing receptor conformations. Proc Natl Acad Sci U S A 104 (13): 5443-5448.

11. Wisler JW, Xiao K, Thomsen AR, Lefkowitz RJ (2014) Recent developments in biased agonism. Current opinion in cell biology 27: 18-24.

12. Strange PG (2002) Mechanisms of inverse agonism at G-protein-coupled receptors. Trends in pharmacological sciences 23 (2): 89-95.

13. Bond RA, Ijzerman AP (2006) Recent developments in constitutive receptor activity and inverse agonism, and their potential for GPCR drug discovery. Tre Trends Pharmacol Sci 27 (2): 92-96.

14. Parra S, Bond RA (2007) Inverse agonism: from curiosity to accepted dogma, but is it clinically relevant? Curr Opin Pharmacol 7 (2): 146-150.

15. Monczor F (2006) Mechanisms of inverse agonism at histamine $\mathrm{H}(2)$ receptors - potential benefits and concerns. Inflammopharmacology 14 (1-2): 89-96.

16. Smit MJ, Leurs R, Alewijnse AE, Blauw J, Van Nieuw Amerongen GP, et al. (1996) Inverse agonism of histamine $\mathrm{H} 2$ antagonist accounts for upregulation of spon- taneously active histamine $\mathrm{H} 2$ receptors. Proc Natl Acad Sci U S A 93 (13): 6802-6807.

17. Osawa S, Kajimura M, Yamamoto S, Ikuma M, Mochizuki C, et al. (2005) Alteration of intracellular histamine $\mathrm{H} 2$ receptor cycling precedes antagonistinduced upregulation. Am J Physiol Gastrointest Liver Physiol 289 (5): G880-889.

18. Sumida Y, Umemura S, Tamura K, Kihara M, Kobayashi $\mathrm{S}$, et al. (1998) Increased cardiac angiotensin II receptors in angiotensinogen-deficient mice. Hypertension 31 (1): 45-49.

19. Lania AG, Mantovani G, Spada A (2006) Mechanisms of disease: Mutations of $\mathrm{G}$ proteins and G-proteincoupled receptors in endocrine diseases. Nat Clin Pract Endocrinol Metab 2 (12): 681-693.

20. Vassart G, Costagliola S (2011) G protein-coupled receptors: mutations and endocrine diseases. $N$ Nat Rev Endocrinol 7 (6): 362-372.

21. Parma J, Duprez L, Van Sande J, Cochaux P, Gervy C, et al. (1993) Somatic mutations in the thyrotropin receptor gene cause hyperfunctioning thyroid adenomas. Nature 365 (6447): 649-651.

22. Feldman BJ, Rosenthal SM, Vargas GA, Fenwick RG, Huang EA, et al. (2005) Nephrogenic syndrome of inappropriate antidiuresis. N Engl J Med 352 (18): 1884-1890.

23. Takahashi K, Makita N, Manaka K, Hisano M, Akioka Y, et al. (2012) V2 vasopressin receptor (V2R) mutations in partial nephrogenic diabetes insipidus highlight protean agonism of V2R antagonists. The J Biol Chem 287 (3): 2099-2106.

24. Pollak MR, Brown EM, Estep HL, McLaine PN, Kifor O, et al. (1994) Autosomal dominant hypocalcaemia caused by a $\mathrm{Ca}(2+)$-sensing receptor gene mutation. Nat Genet 8 (3): 303-307.

25. Koch WJ, Lefkowitz RJ, Rockman HA (2000) Functional consequences of altering myocardial adrenergic receptor signaling. A Annu Rev Physiol 62: 237-260.

26. Siryk-Bathgate A, Dabul S, Lymperopoulos A (2013) Current and future $G$ protein-coupled receptor signaling targets for heart failure therapy. Drug Des Devel Ther 7: 1209-1222.

27. Krum H (2014) Decade in review--heart failure: 10 Years of progress in HF research--what have we learned? Nat Rev Cardiol 11 (11): 631-633.

28. Zhang W, Anger T, Su J, Hao J, Xu X, et al. (2006) Selective loss of fine tuning of $\mathrm{Gq} / 11$ signaling by RGS2 protein exacerbates cardiomyocyte hypertrophy. J Biol Chem 281 (9): 5811-5820.

29. Takefuji M, Wirth A, Lukasova M, Takefuji S, Boettger T, et al. (2012) G(13)-mediated signaling pathway is required for pressure overload-induced cardiac remodel- 
ing and heart failure. Circulation 126 (16): 1972-1982.

30. Tilley DG, Zhu W, Myers VD, Barr LA, Gao E, et al. (2014) beta-adrenergic receptor-mediated cardiac contractility is inhibited via vasopressin type 1A-receptordependent signaling. Circulation 130 (20): 1800-1811.

31. Whalen EJ, Foster MW, Matsumoto A, Ozawa K, Violin JD, et al. (2007) Regulation of beta-adrenergic receptor signaling by S-nitrosylation of G-protein-coupled receptor kinase 2. Cell 129 (3): 511-522.

32. Lymperopoulos A, Rengo G, Koch WJ (2012) GRK2 inhibition in heart failure: something old, something new. Curr Pharm Des 18 (2): 186-191.

33. Makita N, Kabasawa Y, Otani Y, Firman, Sato J, et al. (2013) Attenuated desensitization of beta-adrenergic receptor by water-soluble $\mathrm{N}$-nitrosamines that induce S-nitrosylation without NO release. Circ Res 112 (2): 327-334.

34. Arif SA, Mergenhagen KA, Del Carpio RO, Ho C (2010) Treatment of systolic heart failure in the elderly: an evidence-based review. Ann Pharmacother 44 (10): 1604-1614.

35. Abete P, Testa G, Della-Morte D, Gargiulo G, Galizia G, et al. (2013) Treatment for chronic heart failure in the elderly: current practice and problems. Heart Fail Rev 18 (4): 529-551.

36. Group TCTS (1987) Effects of enalapril on mortality in severe congestive heart failure. Results of the Cooperative North Scandinavian Enalapril Survival Study (CONSENSUS). The CONSENSUS Trial Study Group. N Engl J Med 316 (23): 1429-1435.

37. Investigators TS (1991) Effect of enalapril on survival in patients with reduced left ventricular ejection fractions and congestive heart failure. The SOLVD Investigators. N Engl J Med 325 (5): 293-302.

38. Pfeffer MA, Braunwald E, Moyé LA, Basta L, Brown EJ Jr, et al. (1992) Effect of captopril on mortality and morbidity in patients with left ventricular dysfunction after myocardial infarction. Results of the survival and ventricular enlargement trial. The SAVE Investigators. N Engl J Med 327 (10): 669-677.

39. Investigators TAIREAS (1993) Effect of ramipril on mortality and morbidity of survivors of acute myocardial infarction with clinical evidence of heart failure. The Acute Infarction Ramipril Efficacy (AIRE) Study Investigators. Lancet 342 (8875): 821-828.

40. Køber L, Torp-Pedersen C, Carlsen JE, Bagger H, Eliasen P, et al. (1995) A clinical trial of the angiotensin-converting-enzyme inhibitor trandolapril in patients with left ventricular dysfunction after myocardial infarction. Trandolapril Cardiac Evaluation (TRACE) Study Group. N Engl J Med 333 (25): 1670-1676.

41. Lindholm LH, Ibsen H, Dahlöf B, Devereux RB, Beevers G, et al. (2002) Cardiovascular morbidity and mortality in patients with diabetes in the Losartan Intervention For Endpoint reduction in hyperten- sion study (LIFE): a randomised trial against atenolol. Lancet 359 (9311): 1004-1010.

42. McMurray JJ, Ostergren J, Swedberg K, Granger CB, Held P, et al. (2003) Effects of candesartan in patients with chronic heart failure and reduced left-ventricular systolic function taking angiotensin-converting-enzyme inhibitors: the CHARM-Added trial. Lancet 362 (9386): 767-771.

43. Zou Y, Akazawa H, Qin Y, Sano M, Takano H, et al. (2004) Mechanical stress activates angiotensin II type 1 receptor without the involvement of angiotensin II. Nat Cell Biol 6 (6): 499-506.

44. Makita N, Fujita T, Iiri T (2006) Angiotensin receptor 1a. AfCS Nature Molecule Pages: doi:10.1038/ mp.a000275.01.

45. ONTARGET Investigators, Yusuf S, Teo KK, Pogue J, Dyal L, Copland I, et al. (2008) Telmisartan, ramipril, or both in patients at high risk for vascular events. $N \mathrm{Engl}$ J Med 358 (15): 1547-1559.

46. van Vark LC, Bertrand M, Akkerhuis KM, Brugts JJ, Fox K, et al. (2012) Angiotensin-converting enzyme inhibitors reduce mortality in hypertension: a metaanalysis of randomized clinical trials of renin-angiotensin-aldosterone system inhibitors involving 158,998 patients. Eur Heart J 33 (16): 2088-2097.

47. Hunyady L, Turu G (2004) The role of the AT1 angiotensin receptor in cardiac hypertrophy: angiotensin II receptor or stretch sensor? Trends Endocrinol Metab 15 (9): 405-408.

48. Akazawa H, Yabumoto C, Yano M, Kudo-Sakamoto Y, Komuro I (2013) ARB and cardioprotection. Cardiovasc Drugs Ther 27 (2): 155-160.

49. Hitomi H, Fukui T, Moriwaki K, Matsubara K, Sun GP, et al. (2006) Synergistic effect of mechanical stretch and angiotensin II on superoxide production via NADPH oxidase in vascular smooth muscle cells. J Hypertens 24 (6): 1089-1095.

50. Liu G, Hitomi H, Hosomi N, Lei B, Pelisch N, et al. (2010) Mechanical stretch potentiates angiotensin II-induced proliferation in spontaneously hypertensive rat vascular smooth muscle cells. Hypertens Res 33 (12): 1250-1257.

51. Azzi M, Charest PG, Angers S, Rousseau G, Kohout T, et al. (2003) Beta-arrestin-mediated activation of MAPK by inverse agonists reveals distinct active conformations for $\mathrm{G}$ protein-coupled receptors. Proc Natl Acad Sci U S A 100 (20): 11406-11411.

52. Patel CB, Noor N, Rockman HA (2010) Functional selectivity in adrenergic and angiotensin signaling systems. Mol Pharmacol 78 (6): 983-992.

53. Saulière A, Bellot M, Paris H, Denis C, Finana F, et al. (2012) Deciphering biased-agonism complexity reveals a new active AT1 receptor entity. Nat Chem Biol 8 (7): 622-630.

54. Tang W, Strachan RT, Lefkowitz RJ, Rockman HA 
(2014) Allosteric modulation of beta-arrestin-biased angiotensin II type 1 receptor signaling by membrane stretch. J Biol Chem 289 (41): 28271-28283.

55. Turnbull F, Neal B, Pfeffer M, Kostis J, Algert C, et al. (2007) Blood pressure-dependent and independent effects of agents that inhibit the renin-angiotensin system. J Hypertens 25 (5): 951-958.

56. Brugts JJ, van Vark L, Akkerhuis M, Bertrand M, Fox $\mathrm{K}$, et al. (2015) Impact of renin-angiotensin system inhibitors on mortality and major cardiovascular endpoints in hypertension: A number-needed-to-treat analysis. Int J Cardiol 181: 425-429.

57. Michel MC, Foster C, Brunner HR, Liu L (2013) A sys- tematic comparison of the properties of clinically used angiotensin II type 1 receptor antagonists. Pharmacol Rev 65 (2): 809-848.

58. AbdAlla S, Lother H, el Massiery A, Quitterer U (2001) Increased AT(1) receptor heterodimers in preeclampsia mediate enhanced angiotensin II responsiveness. Nat med 7 (9): 1003-1009.

59. Hansen JL, Hansen JT, Speerschneider T, Lyngsø C, Erikstrup N, et al. (2009) Lack of evidence for AT1R/ B2R heterodimerization in COS-7, HEK293, and NIH3T3 cells: how common is the AT1R/B2R heterodimer? J Biol Chem 284 (3): 1831-1839. 